\title{
Đánh giá biến động độ che phủ thực vật tại một số khu vực đô thị và ven đô Hà Nội từ tư liệu ảnh vệ tinh LANDSAT đa phổ và đa thời gian
}

\author{
Hoàng Anh Huy* \\ Trường Đại học Tài nguyên và Môi trường Hà Nội, 41 A Phú Diến, \\ Bắc Tì̀ Liêm, Hà Nội, Việt Nam \\ Nhận ngày 13 tháng 02 năm 2017 \\ Chỉnh sửa ngày 21 tháng 3 năm 2017; Chấp nhận đăng ngày 28 tháng 6 năm 2017
}

\begin{abstract}
Tóm tắt: Mục tiêu của nghiên cứu là đánh giá biến động độ che phủ thực vật (FVC) khu vực đô thị và ven đô Hà Nội giai đoạn 2007 - 2015 dựa trên mô hình phân tích lẫn phổ tuyến tính hai đối tượng thuần (SMA) từ tư liệu ảnh vệ tinh đa phổ, đa thời gian LANDSAT TM và OLI. Trên cơ sở chỉ số NDVI, ứng dụng mô hình SMA hai đối tượng thuần xác định $\mathrm{FVC}$, sau đó tiến hành đánh giá biến động độ che phủ thực vật. Kết quả nghiên cứu cho thấy: diện tích $\mathrm{FVC}$ giảm $699,8 \mathrm{~km}^{2}$ (chiếm 75,5\%), trung bình FVC giảm $87,5 \mathrm{~km}^{2}$ mỗi năm tại phía Nam huyện Sóc Sơn, phía Đông huyện Đông Anh và quận Gia Lâm, phía Tây huyện Thanh Trì; FVC giảm ở mức trung bình và nhẹ tại quận Cầu Giấy, Bắc, Nam -Từ Liêm và Tây Sóc Sơn; FVC không thay đổi là $184,5 \mathrm{~km}^{2}$ (chiếm 19,9\%) tại các quận Ba Đình, Đống Đa và Hoàn Kiếm; chỉ 44,9 km² có FVC tăng (chiếm 4,9\%), FVC tăng 5,6 km² mỗi năm, xuất hiện tại quận Hoàng Mai, Đông - Bắc Sóc Sơn, Nam huyện Đông Anh.
\end{abstract}

Tù khóa: Ảnh vệ tinh LANDSAT, biến động độ che phủ thực vật, thành phố Hà Nội.

\section{1. Đặt vấn đề}

Thảm thực vật đóng một vai trò quan trọng trong việc trao đổi carbon, nước và năng lượng trên bề mặt trái đất $[1,2]$, do đó thảm thực vật là một yếu tố quan trọng để giải thích cho việc trao đổi này $[3,4]$. Độ che phủ (Fractional Vegetation Cover - FVC) là một trong những thông số sinh lý chủ yếu liên quan đến các quá trình trao đổi bề mặt, đồng thời nó còn là một thông số cần thiết trong dự báo thời tiết bằng phương pháp số (Numerical Weather

\footnotetext{
*ĐT.: 84-932249680.

Email: hahuy@hunre.edu.vn

https://doi.org/10.25073/2588-1094/vnuees.4097
}

Prediction), mô hình hóa khí hậu toàn cầu và khu vực, và quan trắc sự thay đổi toàn cầu $[5$, 6]. Độ che phủ thực vật cũng là một thông số quan trọng trong viễn thám nhiệt, vì nó là một thông số cơ bản cho phép xác định độ phát xạ bề mặt [7]. Hiện nay, hai phương pháp chủ yếu để xác định độ che phủ thực vật là đo đạc ngoài thực địa và phương pháp viễn thám [8]. Đo đạc ngoài thực địa là phương pháp truyền thống bao gồm phương pháp ước lượng bằng mắt, phương pháp lấy mẫu và phương pháp sử dụng các thiết bị đo chuyên dụng với các chế độ đo khác nhau [9]. Đây là phương pháp đóng vai trò chủ yếu trong khảo sát của độ che phủ của thảm thực vật trên bề mặt đất. Tuy nhiên với sự phát triển mạnh mẽ của công nghệ viễn thám, phương 
pháp viễn thám đang là một công cụ hiệu quả trong xác định độ che phủ thực vật, thậm chí có thể theo dõi sự phân bố và phát triển của $\mathrm{FVC}$ [10]. Với ưu điểm vượt trội về khả năng thu nhận ảnh trên quy mô lớn và phát hiện định kỳ, tư liệu ảnh vệ tinh cho phép xác định độ che phủ thực vật và đánh giá biến động trên một khu vực rộng lớn nên đây là phương pháp đang được ứng dụng một cách rộng rãi [11, 12]. Trong hầu hết các nghiên cứu, có ba phương pháp cơ bản để xác định độ che phủ thực vật từ tư liệu ảnh vệ tinh gồm có mô hình hồi quy, phương pháp chỉ số thực vật (vegetation index) và phân tích lẫn phổ tuyến tính đa đối tượng thuần (multi-endmember linearspectral mixture analysis - SMA) [13, 14]. Đối với tư liệu ảnh LANDSAT, chỉ sử dụng tối đa được bốn đối tượng thuần trong mô hình SMA vì độ tương quan giữa ba băng tần trong dải ánh sáng nhìn thấy rất lớn $[15,16]$.Trong nghiên cứu này, mô hình phân tích lẫn phổ tuyến tính (SMA) hai đối tượng thuần được sử dụng để xác định độ che phủ thực vật, từ đó làm cơ sở để tiến hành đánh giá biến động.

Hà Nội là thành phố đã và đang bị ảnh hưởng mạnh mẽ bởi biến đổi khí hậu và quá trình đô thị hóa nhanh chóng. Đây là một trong những nguyên nhân làm cho môi trường sinh thái (đất, nước và không khí) bị ô nhiễm một cách nghiêm trọng, đặc biệt là làm suy giảm độ che phủ của thảm thực vật. Độ che phủ thảm thực vật bị suy giảm và thay thế bằng các bề mặt không thấm hoặc các tòa nhà chính là nguyên nhân chủ yếu gây ra hiện tượng đảo nhiệt đô thị. Do đó nghiên cứu sự thay đổi về độ che phủ thực vật có ý nghĩa đặc biệt quan trọng, đặc biệt tại các khu vực có mức độ đô thị hóa nhanh chóng như ven đô Hà Nội. Mục tiêu của nghiên cứu nhằm đánh giá biến động độ che phủ một số khu vực đô thị và ven đô Hà Nội (giới hạn tại các quận huyện trước khi Hà Nội mở rộng) giai đoạn từ 2007 đến 2015 ứng dụng mô hình phân tích lẫn phổ tuyến tính hai đối tượng thuần (two endmember linear SMA) từ tư liệu ảnh LANDSAT đa phổ, đa thời gian.

\section{Tư liệu sử dụng và phương pháp nghiên cứu}

\subsection{Tu liệu sủ dụng}

Tư liệu sử dụng trong nghiên cứu là ảnh vệ tinh LANDSAT 5 TMvà 8 OLIcó độ phân giải không gian $30 \mathrm{~m}$ tải về từ trang web của Cục Điều tra Địa chất Hoa kỳ (USGS) [17]. Ảnh vệ tinh LANDSAT $5 \mathrm{TM}$ và $8 \mathrm{OLI}$ lần lượt được thu nhận vào $24 / 5 / 2007$ và $01 / 07 / 2015$, đều được chuẩn định với hệ quy chiếu WGS 1984 UTM, Zone 48 North ở mức L1T (đã hiệu chỉnh bức xạ do ảnh hưởng của sai số hệ thống và hiệu chỉnh hình học). Thông tin mô tả về 2 ảnh vệ tinh LANDSAT được tổng hợp trong Bảng 1.

Bảng 1. Bảng tổng hợp các thông số mô tả tư liệu ảnh vệ tinh LANDSAT TM và OLI.

\begin{tabular}{|c|c|c|c|c|}
\hline \multirow[b]{2}{*}{ STT } & \multirow{2}{*}{\multicolumn{2}{|c|}{ Thông tin ảnh vệ tinh }} & \multicolumn{2}{|l|}{ Thông số mô tả } \\
\hline & & & LANDSAT 5 TM & LANDSAT 8 OLI \\
\hline 1 & \multicolumn{2}{|l|}{ Mức dữ liệu } & L1T & L1T \\
\hline 2 & \multicolumn{2}{|l|}{ Tỷ lệ mây } & $1 \%$ & $4.16 \%$ \\
\hline 3 & \multicolumn{2}{|l|}{ Chất lượng ảnh } & $7 / 9$ & 9/9 \\
\hline 4 & \multicolumn{2}{|l|}{ Băng tần sử dụng tính $\mathrm{FVC}$} & 3,4 & 4,5 \\
\hline 5 & \multicolumn{2}{|l|}{ Độ phân giải không gian } & $30 \mathrm{~m}$ & $30 \mathrm{~m}$ \\
\hline 6 & \multicolumn{2}{|l|}{ Thời gian thu nhận ảnh } & $24-05-2007$ & 01-07-2015 \\
\hline \multirow{2}{*}{7} & \multirow{2}{*}{ Điểm khống chế mặt đất } & Số lượng & 168 & 302 \\
\hline & & \multirow[t]{2}{*}{ Nguồn dữ liệu } & GLS2000 & GLS2000 \\
\hline 8 & Nguồn dữ liệu DEM & & SRTM & SRTM \\
\hline \multirow{3}{*}{9} & \multirow{3}{*}{$\begin{array}{l}\text { Độ chính xác hiệu chỉnh hình } \\
\text { học }\end{array}$} & Sai số trung bình & $4.051 \mathrm{~m}$ & $8.118 \mathrm{~m}$ \\
\hline & & Sai số hướng dọc & $2.795 \mathrm{~m}$ & $6.261 \mathrm{~m}$ \\
\hline & & Sai số hướng ngang & $2.933 \mathrm{~m}$ & $5.168 \mathrm{~m}$ \\
\hline 10 & \multicolumn{2}{|c|}{ Phần mềm sử dụng hiệu chỉnh hình học } & LPGS 2.5.0 & LPGS 2.5.1 \\
\hline
\end{tabular}


Trong quá trình hiệu chỉnh hình học ảnh LANDSAT TM và OLI đã sử dụng 168 và 302 điểm khống chế mặt đất (GCPs) lấy từ cơ sở dữ liệu toàn cầu (GLS2000) và mô hình số độ cao (DEM) để hiệu chỉnh ảnh hưởng của địa hình bằng phần mềm LPGS. Dữ liệu DEM được thu thập từ dữ liệu vệ tinh SRTM có độ phân giải ngang $30 \mathrm{~m}$ và độ chính xác tương đối $10 \mathrm{~m}$. Sai số trung phương trọng số đơn vị hiệu chỉnh hình học trung bình, theo hướng dọc và hướng ngang đối với ảnh LANDSAT 5 TM là $4.051 \mathrm{~m}$, $2.795 \mathrm{~m}, 2.933 \mathrm{~m}$ và LANDSAT 8 OLI là $8.118 \mathrm{~m}, 6.261 \mathrm{~m}, 5.168 \mathrm{~m}$.

\subsection{Phưong pháp nghiên cúu}

2.2.1. Chuyển đổi giá trị số nguyên của ảnh sang giá trị phản xa phổ ở đỉnh khi quyển

Quá trình chuyển giá trị số nguyên (DN values) của ảnh sang giá trị phản xạ phổ ở đỉnh khí quyển (top of atmosphere (TOA) reflectance) gồm hai bước. Bước đầu tiên là chuyển giá trị số nguyên sang giá trị bức xạ phổsử dụng các thông số hiệu chuẩn cảm biến trong quá trình thu nhận ảnh từ vệ tinh. Giá trị bức xạ phổ được chuyển đổi thông qua công thức (1) đối với ảnh LANDSAT 5 TM và công thức (2) đối với ảnh LANDSAT 8 OLI:

$L_{\lambda}=\frac{\operatorname{Lmax}_{\lambda}-\operatorname{Lmin}_{\lambda}}{Q_{\text {calmax }}-Q_{\text {calmin }}}\left(Q_{\text {cal }}-Q_{\text {calmin }}\right)+L \min$

trong đó: $L_{\lambda}$ là giá trị bức xạ phổ $\left[\mathrm{W} /\left(\mathrm{m}^{2} . \mathrm{sr} . \mu \mathrm{m}\right)\right] ; Q_{\text {cal }}$ là giá trị số nguyên của ảnh; $Q_{\text {calmax }}$ là giá trị số nguyên lớn nhất

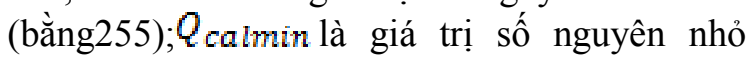
nhất (bằng1); $\operatorname{Lmax}_{\lambda}, \operatorname{Lmin}_{\lambda}$ lần lượt là giá trị bức xạ phổ tương ứng với $Q_{\text {calmax }}$ và $Q_{\text {calmin }}$ ở từng kênh phổ (Bảng 2).

$$
L_{\lambda}=M_{L} \cdot Q_{c a l}+A_{L}
$$

trong đó: $M_{L}, A_{L}$ lần lượt là hệ số chuyển

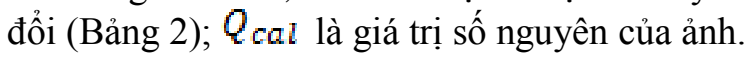

Bảng 2. Bảng tổng hợp các thông số hiệu chuẩn cảm biến cho ảnh LANDSAT 5 TM và $8 \mathrm{OLI}$ sử dụng trong khu vực nghiên cứu

\begin{tabular}{lllllll}
\hline STT & Tư liệu & Kênh & $\operatorname{Lmax}_{\boldsymbol{\lambda}}$ & $\mathbf{L m i n}_{\boldsymbol{\lambda}}$ & $\mathbf{M}_{\mathbf{L}}$ & $\mathbf{A}_{\mathbf{L}}$ \\
\hline \multirow{2}{*}{1} & \multirow{2}{*}{ LANDSAT 5 TM } & 3 & 264.000 & -1.170 & - & - \\
& & 4 & 221.000 & -1.510 & - & - \\
2 & \multirow{2}{*}{ LANDSAT 8 OLI } & 4 & - & - & $9.6667 \mathrm{E}-03$ & -29.57771 \\
& & 5 & - & - & $5.9155 \mathrm{E}-03$ & -48.33352 \\
\hline
\end{tabular}

Bước tiếp theo là xác định giá trị phản xạ phổ ở đỉnh khí quyển đối với mỗi kênh thông qua công thức (3):

$$
\rho_{\lambda}=\frac{\pi \mathbf{d}^{2} \mathbf{L}_{\lambda}}{\mathbf{E}_{0 \lambda} \cos \theta_{s}}
$$

trong đó: $\rho_{\lambda}$ là giá trị phản xạ phổ ở đỉnh khí quyển của một kênh; d là khoảng cách thiên văn giữa Trái đất và Mặt trời; $\mathbf{L}_{\lambda}$ là giá trị bức xạ phổ chuyển đổi được từ bước trên; $\mathbf{E}_{0 \lambda}$ là giá trị trung bình bức xạ quang phổ mặt trời; $\theta_{s}$ là góc thiên đỉnh (lấy trong file metadata ảnh LANDSAT).

\subsubsection{Hiệu chỉnh ảnh hương của khí quyển}

Trong nghiên cứu này, phương pháp trừ đối tượng tối (Dark Object Subtraction - DOS) 1\% do Chavez đề xuất được ứng dụng để hiệu chỉnh ảnh hưởng khí quyển [18]. Đây là phương pháp đã được áp dụng thành công trong một số nghiên cứu đối với ảnh vệ tinh LANDSAT để làm giảm ảnh hưởng của tán xạ ánh sáng đến chất lượng ảnh vệ tinh [19].

\subsubsection{Xác định biến động độ che phủ thực vật ( $F V C C)$}

Mô hình phân tích lẫn phổ tuyến tính (SMA) đa đối tượng thuần tổng quát do Van đề xuất được thể hiện bởi công thức sau [20]: 


$$
\mathbf{R}_{\mathrm{k}}=\sum_{\mathrm{i}=1}^{\mathbf{n}} \mathbf{f}_{\mathrm{i}} \mathbf{r}_{\mathrm{i}, \mathrm{k}}+\mathbf{e}_{\mathrm{k}}
$$

trong đó: $\mathbf{R}_{\mathbf{k}}$ là giá trị phản xạ phổ của kênh $\mathrm{k} ; \mathrm{n}$ là số lượng các đối tượng thuần trong một pixel hỗn hợp; $\mathbf{f}_{\mathbf{i}}$ là tỷ lệ của đối tượng thuần i trong một pixel hỗn hợp; $\mathbf{r}_{\mathbf{i}, k}$ là giá trị phản xạ phổ của đối tượng thuần $\mathrm{i}$ tại kênh $\mathrm{k}$ trong pixel hỗn hợp; $\mathbf{e}_{\mathbf{k}}$ là phần dư khớp mô hình tại kênh $\mathrm{k}$. Các đối tượng thuần trong pixel hỗn hợp thỏa mãn điều kiện:

$$
\sum_{i=1}^{n} f_{i}=1
$$

Trong nghiên cứu của Deardorff đã chứng minh, hệ số độ ẩm và nhiệt là hàm tuyến tính của độ che phủ thực vật [21]. Mô hình toán học dạng tổng quát thể hiện mối quan hệ tuyến tính này được thể hiện trong công thức (6):

$$
\Phi=(1-\sigma) \times \Phi_{\sigma=0}+\sigma \times \Phi_{\sigma=1}
$$

trong đó: $\Phi$ là hệ số độ ẩm hay nhiệt, $\Phi_{\sigma=0}$ và $\Phi_{\sigma=1}$ lần lượt là thành phần đóng góp của thực vật và thổ nhưỡng trong đó. Wittich và Hansing đã áp dụng công thức chung này cho chỉ số thực vật (NDVI) trong việc xác định độ che phủ thực vật (FVC) sử dụng mô hình phân tích lẫn phổ tuyến tính (LSMA) với hai đối tượng thuần [22]:

$$
\mathbf{N D V I}=f * \mathbf{N D V I}_{\text {veg }}+(\mathbf{1}-f) * \mathbf{N D V I}_{\text {soil }}
$$

và có thể được viết lại như sau:

$$
f=\frac{\mathbf{N D V I}-\mathbf{N D V I}_{\text {soil }}}{\mathbf{N D V I}_{\text {Veg }}-\mathbf{N D V I}_{\text {soil }}}
$$

trong đó: $f$ là tỉ lệ thực vật trong một pixel hỗn hợp, chính là độ che phủ thực vật (FVC),

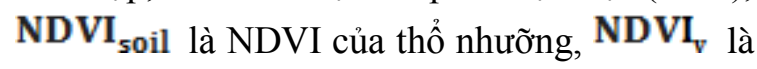
NDVI của thực vật, NDVI là NDVI của pixel hỗn hợp và được xác định bởi công thức (9) [23].

$$
\text { NDVI }=\frac{\rho_{\mathrm{NIR}}-\rho_{\mathrm{RED}}}{\rho_{\mathrm{NIR}}+\rho_{\mathrm{RED}}}
$$

Việc xác định giá trị chính xác của NDVI $_{\text {veg và }}$ NDVI $_{\text {soill là điều khó khăn vì tồn }}$ tại nhiều tính bất định do chúng chịu ảnh hưởng của các loại thổ nhưỡng, loại thực vật khác nhau, hàm lượng chất diệp lục và các yếu tố khác. Đối với các nghiên cứu ở khu vực lớn (mang tính chất toàn cầu) sử dụng ảnh vệ tinh có độ phân giải không gian thấp $\left(0.15^{\circ} \times 0.15^{\circ}\right)$, Gutman and Ignatov đã đề xuất giá trị $\mathrm{NDVI}_{\text {soil }}$ $=0.04 \pm 0.03$ và $\mathrm{NDVI}_{\text {veg }}=0.52 \pm 0.03$, tương ứng với giá trị nhỏ nhất và giá trị lớn nhất tại sa mạc và nơi tập trung nhiều cây xanh [3]. Trong khi đó, đối với ảnh có độ phân giải không gian trung bình, Sobrino and Raissouni đề xuất một giá trị khá tương đồng là $\mathrm{NDVI}_{\mathrm{veg}}=0.5$, và $\mathrm{NDVI}_{\text {soil }}=0.2$. Trong nghiên cứu này, $\mathrm{NDVI}_{\mathrm{veg}}$ và $\mathrm{NDVI}_{\text {soil }}$ được xác định từ kết quả nghiên cứu của Sobrino [24]. Khi đó, nếu NDVI $>0.5$ thì pixel đó được coi là hoàn toàn bao phủ bởi thực vật (đối tượng thuần thực vật), độ che phủ thực vật $f=1$. Nếu NDVI $<0.2$ thì pixel đó được coi là hoàn toàn bao phủ bởi thổ nhưỡng (đối tượng thuần thổ nhưỡng), độ che phủ thực vật $f=0$. Nếu $0.2<\mathrm{NDVI}<0.5$ thì độ che phủ thực vật (FVC) được xác định theo công thức (8).

Việc xác định biến động độ che phủ thực vật (FVCC) được xác định bằng phương pháp trừ raster. Trong nghiên cứu này, mức độ biến động của $\mathrm{FVC}$ được chia thành 7 cấp độ khác hhau: cấp 1,2 và 3 thể hiện sự giảm $\mathrm{FVC}$ ở Mhức độ mạnh, trung bình và nhẹ, lần lượt dao động từ $-100 \%$ đến $-70 \%,-70 \%$ đến $-30 \%$ và $30 \%$ đến $-10 \%$; cấp độ 4 thể hiện hầu như không có sự thay đổi về $\mathrm{FVC}$, dao động từ $10 \%$ đến $10 \%$; cấp 5,6 và 7 thể hiện sự tăng FVC ở mức nhẹ, trung bình và mạnh, dao động từ $10 \%$ đến $20 \%, 30 \%$ đến $70 \%$, và $70 \%$ đến $100 \%$.

\section{Kết quả và thảo luận}

Kết quả xác định biến động độ che phủ thực vật trên khu vực nghiên cứu được tổng hợp trong Bảng 2 và thể hiện qua Hình 1, 2. Biểu đồ 
tần xuất thể hiện biến động độ che phủ thực vật cho thấy, sự phân bố về biến động độ che phủ thực vật không cân bằng,diện tích các vùng có độ che phủ thực vật bị giảm lớn hơn nhiều so với các khu vực có độ che phủ thực vật tăng lên, đồng thời phân bố lệch hẳn sang bên trái so với tại vị trí trung tâm (nơi hầu như không có biến động, độ che phủ thực vật bằng 0 ).

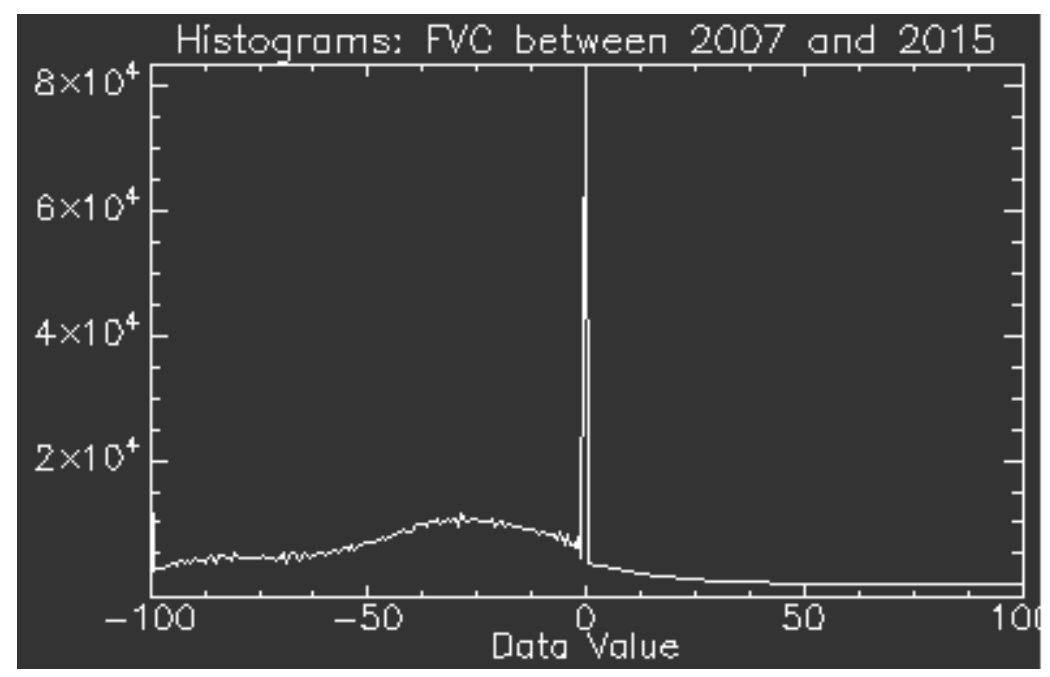

Hình 1. Biểu đồ tần xuất biến động độ che phủ thực vật (FVCC) tại một số khu vực đô thị và ven đô Hà Nội giai đoạn $2007-2015$.

Bảng 2. Bảng tổng hợp kết quả biến động độ che phủ thực vật giai đoạn 2007 - 2015

\begin{tabular}{lllllll}
\hline STT & Mức biến động & $\begin{array}{l}\text { Phạm vi } \\
\text { biến động }(\%)\end{array}$ & $\begin{array}{l}\text { Diện tích } \\
\left(\mathrm{km}^{2}\right)\end{array}$ & $\begin{array}{l}\text { Diện tích } \\
\text { tích lũy }\left(\mathrm{km}^{2}\right)\end{array}$ & $\begin{array}{l}\text { Tỷ lệ } \\
(\%)\end{array}$ & $\begin{array}{l}\text { Tỷ lệ } \\
\text { tích lũy }(\%)\end{array}$ \\
\hline 1 & Giảm mạnh & {$[-100,-70]$} & 155.3 & 155.3 & 16.7 & 16.7 \\
2 & Giảm trung bình & {$[-70,-30]$} & 326.0 & 481.3 & 35.1 & 51.8 \\
3 & Giảm nhẹ & {$[-30,-10]$} & 218.5 & 699.8 & 23.5 & 75.3 \\
4 & Không thay đổi & {$[-10,10]$} & 184.5 & 884.3 & 19.9 & 95.2 \\
5 & Tăng nhẹ & {$[10,30]$} & 28.5 & 912.8 & 3.1 & 98.2 \\
6 & Tăng trung bình & {$[30,70]$} & 13.8 & 926.6 & 1.5 & 99.7 \\
7 & Tăng mạnh & {$[70,100]$} & 2.7 & 929.2 & 0.3 & 100.0 \\
\multicolumn{1}{l}{ Tổng cộng: } & & 929.2 & 929.2 & 100.0 & 100.0 \\
\hline
\end{tabular}

Từ bảng tổng hợp kết quả biến động độ che phủ thực vật (Bảng 2) và sự phân bố về biến động (Hình 2) cho thấy: diện tích có độ che phủ giảm mạnh đạt $155.3 \mathrm{~km}^{2}$ chiếm $16.7 \%$ tổng diện tích khu vực nghiên cứu $\left(929.2 \mathrm{~km}^{2}\right)$, chủ yếu tập trung ở các khu vực phía bắc huyện Sóc Sơn và huyện Đông Anh; khu vực có độ che phủ giảm ở mức trung bình chiếm diện tích tương đối lớn với $326,0 \mathrm{~km}^{2}$ (chiếm $35.1 \%$ tổng diện tích), chủ yếu tập trung ở các khu vực Bắc - Nam Từ Liêm, phía Tây huyện Thanh Trì, phía Đông quận Gia Lâm; 218 km² diện tích có độ che phủ thực vật bị suy giảm ở mức nhẹ, chủ yếu tập trung ở các quận Long Biên và một số khu vực thuộc huyện Sóc Sơn. Như vậy có thể thấy, về tổng thể, độ che phủ thực vật bị suy giảm chiếm phần lớn diện tích khu vực nghiên cứu với tổng cộng $699,8 \mathrm{~km}^{2}$ (chiếm $75.3 \%$ tổng diện tích). Diện tích độ che phủ thực vật hầu như không thay đổi đạt $184.5 \mathrm{~km}^{2}$ (chiếm $19.9 \%$ tổng diện tích), chủ yếu xuất hiện tại một số khu vực thuộc các quận Ba Đình, Đống Đa và Hoàn Kiếm. Trong khi đó những khu vực có độ che phủ tăng nhẹ tương đối ít chỉ chiếm 28.5 
$\mathrm{km}^{2}$ (chiếm $3.1 \%$ trên tổng diện tích); độ che phủ tăng ở mức trung bình đạt diện tích 13.8 $\mathrm{km}^{2}$ (chiếm $1.5 \%$ tổng diện tích). Chỉ có diện tích rất nhỏ (hầu như không đáng kể) có độ che phủ thực vật tăng mạnh với $2.7 \mathrm{~km}^{2}$ (chiếm
$0.3 \%$ tổng diện tích), chủ yếu xuất hiện ở khu vực ven đô Hà Nội như các khu vực thuộc Đông Bắc huyện Sóc Sơn, phía Đông huyện Đông Anh và quận Hoàng Mai.

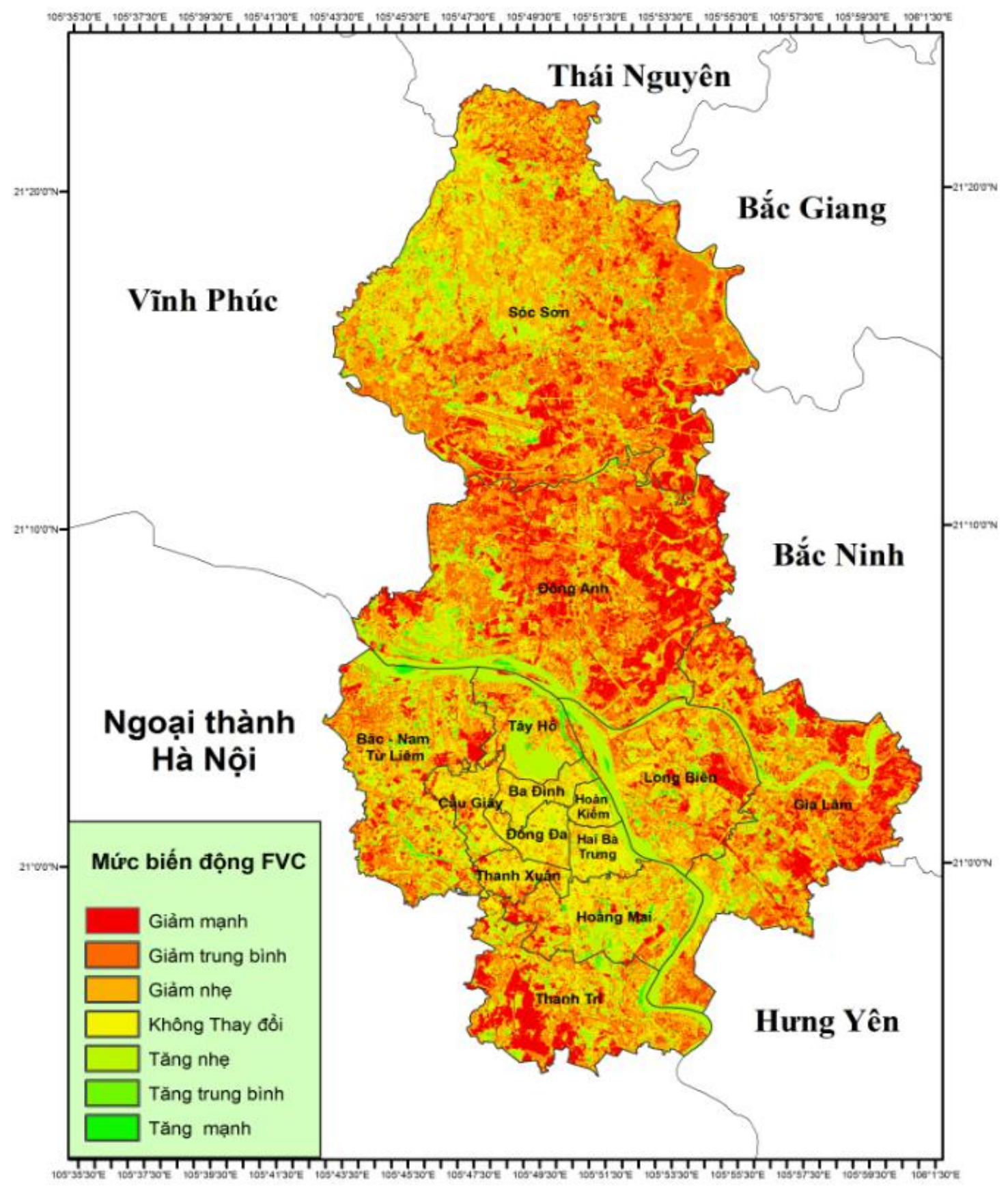

Hình 2. Biến động độ che phủ thực vật tại một số khu vực đô thị và ven đô Hà Nội giai đoạn 2007 - 2015. 
Về tổng thể có thể thấy, độ che phủ khu vực nghiên cứu đã bị suy giảm một cách mạnh mẽ trong 8 năm từ năm 2007 đến năm 2015, tổng diện tích độ che phủ thực vật bị suy giảm là $699.8 \mathrm{~km}^{2}$ (chiếm $75.5 \%$ tổng diện tích), trung bình có $87.5 \mathrm{~km}^{2}$ diện tích bị suy giảm mỗi năm; tổng diện tích có độ che phủ không thay đổi là $184.5 \mathrm{~km}^{2}$ (chiếm $19.9 \%$ ); tổng diện tích độ che phủ tăng lên chỉ đạt $44.9 \mathrm{~km}^{2}$ (chiếm $4.9 \%$ ), trung bình 1 năm độ che phủ tăng rất ít (không đáng kể) với 5.6 km².

\section{Kết luận}

Nghiên cứu đã tiến hành đánh giá biến động độ che phủ thực vật tại một số khu vực đô thị và ven đô Hà Nội giai đoạn 2007 - 2015 ứng dụng mô hình phân tích lẫn phổ tuyến tính (LSMA) hai đối tượng thuần từ tư liệu ảnh vệ tinh Landsat $\mathrm{TM}$ và $\mathrm{OLI}$. Kết quả nghiên cứu cho thấy: (i) độ che phủ bị suy giảm một cách nghiêm trọng giai đoạn này, tồng diện tích độ che phủ thực vật bị suy giảm là $699.8 \mathrm{~km}^{2}$ (chiếm $75.5 \%$ tổng diện tích), như vậy trung bình có $87.5 \mathrm{~km}^{2}$ diện tích bị suy giảm độ che phủ, độ che phủ giảm mạnh tập trung ở các khu vực thuộc phía Nam huyện Sóc Sơn, phía Đông huyện Đông Anh, Gia Lâm và phía Tây huyện Thanh Trì; một số khu vực có độ che phủ giảm trung bình và nhẹ như tại các quận Cầu Giấy, Bắc - Nam Từ Liêm, và phía Tây huyện Sóc Sơn; (ii) tổng diện tích độ che phủ hầu như không thay đổi là $184.5 \mathrm{~km}^{2}$, chiếm $19.9 \%$ tổng diện tích, chủ yếu xuất hiện ở các quận nội thành như Ba Đình, Đống Đa, Hoàn Kiếm; (iii) tổng diện tích độ che phủ tăng lên chỉ đạt 44.9 $\mathrm{km}^{2}$, chiếm $4.9 \%$ tổng diện tích, trung bình 1 năm độ che phủ tăng rất ít (không đáng kể) với $5.6 \mathrm{~km}^{2}$, chủ yếu tập trung ở các khu vực thuộc ở các quận Hoàng Mai, Đông Bắc huyện Sóc Sơn, phía Nam huyện Đông Anh. Từ kết quả nghiên cứu có thể rút ra kết luận là ứng dụng mô hình phân tích lẫn phổ tuyến tính (LSMA) hai đối tượng thuần cho phép xác định và đánh giá độ biến động che phủ thực vật từ tư liệu ảnh vệ tinh LANDSAT một cách hiệu quả và nhanh chóng.

\section{Tài liệu tham khảo}

[1] W. A. Hoffmann, R. Jackson, Vegetation-climate feedbacks in the conversion of tropical savanna to grassland, Journal of Climate, 13 (2000) 1593.

[2] R. C. Ward, M. Robinson, Principles of Hydrology (4th edition), McGraw hill, 2000.

[3] G. Gutman, A. Ignatov, The derivation of the green vegetation fraction from NOAA/AVHRR data for use in numerical weather prediction models, International Journal of Remote Sensing, 19 (8) (1998) 1533.

[4] X. Zeng, R. E. Dickinson, A. Walker, M. Shaikh, Derivation and evaluation of global $1-\mathrm{km}$ fractional vegetation cover data for land modeling, Journal of Applied Meteorology, 39 (2000) 826.

[5] R. Avissar; R. A. Pielke, A parameterization of heterogeneous land surfaces for atmospheric numerical models and its impact on regional meteorology, Monthly Weather Review, 117 (1989) 2113.

[6] S. W. Trimble, Geomorphic effects of vegetation cover and management: some time and space considerations in prediction of erosion and sediment yield, in Vegetation and Erosion, edited by J. B. Thornes, John Wiley \& Sons, London, 1990.

[7] J. C. Jiménez-Muñoz, J. A. Sobrino, A. Plaza, L. Guanter, J. Moreno and P. Martínez, Comparison Between Fractional Vegetation Cover Retrievals from Vegetation Indices and Spectral Mixture Analysis: Case Study of PROBA/CHRIS Data Over an Agricultural Area, Sensors, 9 (2009) 768.

[8] Y. Li, H. Wang and X. B. Li, Fractional Vegetation Cover Estimation Based on an Improved Selective Endmember Spectral Mixture Model, PLoS One, 10(4) (2015) e0124608.

[9] Y. Zhang, X. Li, Y. Chen, Overview of field and multi-scale remote sensing measurement approaches, Advance Earth Sci, 18(1) (2003) 85.

[10] J. L. Silván-Cárdenas, L. Wang, Retrieval of subpixel Tamarix canopy cover from LANDSAT data along the Forgotten River using linear and nonlinear spectral mixture models, Remote Sens Environ, 114(8) (2010) 1777.

[11] F. Chen, Q. Qiu, Y. Xiong, S. Huang, Pixel unmixing based on linear spectral mixture model: methods and comparison, Remote Sens Info, 4 (2010) 22.

[12] Z. Xing, Y. Feng, G. Yang, P. Wang, W. Huang, Method of estimating vegetation coverage 
based on remote sensing, Remote Sens Tech Appl, 24(6) (2009) 849.

[13] M. Li, The method of vegetation fraction estimation by remote sensing, Chinese Academy of Sciences, Beijing, 2003.

[14] X. Li, Quantitive retrieval of sparse vegetation cover in arid regions using hyperspectral data, Chinese Acanemy of Forestry, Beijing, 2008.

[15] C. Small, Estimation of urban vegetation abundance by spectral mixture analysis, International Journal of Remote Sensing, 22 (2001) 1305

[16] M. A. Theseira, G. Thomas, C. A. D. Sannier, An evaluation of spectral mixture modeling applied to a semi-arid environment, International Journal of Remote Sensing, 23 (2002) 687.

[17] https://www.usgs.gov/

[18] P. S. Jr. Chavez. Image-Based Atmospheric Corrections - Revisited and Improved, Photogrammetric Engineering and Remote Sensing, 62(9) (1996) 1025.

[19] C. Song, C. E. Woodcock, K. C. Seto, M. P. Lenney and A. M. Scott, Classification and Change Detection Using LANDSAT TM Data:
When and How to Correct Atmospheric Effects?, Remote Sensing of Environment 75 (2001) 230.

[20] F. Van der Meer, Image classification through spectral unmixing. In: Spatial Statistics for Remote Sensing, Stein, A., Van der Meer, F. \& Gorte, B. (Eds.), Kluwer Academic Publishers, Dordrecht, 1999.

[21] J. W. Deardorff, Efficient prediction of ground temperature and moisture with inclusion of a layer of vegetation, Journal of Geophysical Research, 83 (1978) 1889.

[22] K. P. Wittich, O. Hansing, Area-averaged vegetative cover fraction estimated from satellite data, International Journal of Biometeorology, 38 (1995) 209.

[23] J.W. Rouse, R. H. Haas; J. A. Schell, D. W. Deering, Monitoring vegetation systems in the Great Plains with ERTS In Proc. ERTS-1 Symposium 3rd, Greenbelt, Washington, NASA, 1974.

[24] J. A. Sobrino, N. Raissouni, Toward remote sensing methods for land cover dynamic monitoring: application to Morocco, International Journal of Remote Sensing, 21(2) (2000), 353.

\title{
Assessment of Fractional Vegetation Cover Changes in some Urban and Sub-urban Areas of Hanoi Using Multi-spectral and Multi-temporal LANDSAT Images
}

\author{
Hoang Anh Huy \\ Ha Noi University of Natural Resources and Environtment, \\ 41A Phu Dien, Bac Tu Liem, Hanoi, Vietnam
}

\begin{abstract}
The objective of the study is to assess changes of FVC in some urban and sub-urban areas of Hanoi city 2007 to 2015 based on a two endmember spectral mixture analysis (SMA) model using multi-spectral and multi-temporal LANDSAT TM and OLI images. FVC was estimated for the years of 2007 and 2015 by means of two endmember SMA based on NDVI, the assessment of FVC changes was finally carried out. The study results show that: FVC was decreased with the total area of $699.8 \mathrm{~km}^{2}$, accounting for $75.5 \%$ of total area, decreased by $87.5 \mathrm{~km}^{2}$ per year in Soc Son's south, Dong Anh's east, Gia Lam's east and Thanh Tri's west; some areas had medium and weak decrease rate such as Cau Giay, North and South -Tu Liem and Soc Son's west; total area of almost unchange in FVC was $184.5 \mathrm{~km}^{2}$, accounting for $19.9 \%$, occurring mainly in Ba Dinh, Dong Da, Hoan Kiem; only $44.9 \mathrm{~km}^{2}$ was increased, accounting for $4.9 \%$ of total area, only $5.6 \mathrm{~km}^{2}$ per year, mainly concentrated in the district of Hoang Mai, noth-eastern Soc Son, Dong Anh's south.
\end{abstract}

Keywords: LANDSAT images; fractional vegetation cover change, Ha Noi city. 